\title{
Community structure and collapses in multi-channel food webs: role of consumer body sizes and mesohabitat productivities.
}

\author{
Samuel Dijoux ${ }^{1}$ and David Boukal ${ }^{1}$ \\ ${ }^{1}$ University of South Bohemia in Ceske Budejovice Faculty of Science
}

December 4, 2020

\begin{abstract}
Multi-channel food webs are shaped by the ability of apex predators to link asymmetric energy flows in mesohabitats differing in productivity and community traits. While body size is a fundamental trait underlying life histories and demography, its implications for structuring multi-channel food webs are unexplored. To fill this gap, we develop a framework that links population responses to predation and resource availability to community-level patterns using a tri-trophic food web model with two populations of intermediate consumers and a size-selective top predator. We show that asymmetries in mesohabitat productivities and consumer body sizes drive food web structure, merging previously separate theory on apparent competition and emergent Allee effects (i.e., abrupt collapses of top predator populations). Our results yield theoretical support for empirically observed stability of asymmetric multi-channel food webs and discover three novel types of emergent Allee effects involving intermediate consumers, multiple populations or multiple alternative stable states.
\end{abstract}

\section{Hosted file}

DijouxBoukal_main.pdf available at https://authorea.com/users/381268/articles/497075community-structure-and-collapses-in-multi-channel-food-webs-role-of-consumer-bodysizes-and-mesohabitat-productivities 